Daniel Sierra ${ }^{1}$

\title{
MR. FREGE, THE PLATONIST
}

Abstract. Even though Frege is a major figure in the history of analytic philosophy, it is not surprising that there are still issues surrounding his views, interpreting them, and labeling them. Frege's view on numbers is typically termed as 'Platonistic' or at least a type of Platonism (Reck 2005). Still, the term 'Platonism' has views and assumptions ascribed to it that may be misleading and leads to mischaracterizations of Frege's outlook on numbers and ideas. So, clarification of the term 'Platonism' is required to portray Frege's views more accurately (Reck 2005). This clarification gives us a better picture of what Frege is interested in and what he does not emphasize. Moreover, in such a clarifying process, we find that Frege draws significant influence from Rudolf Hermann Lotze, who is frequently called a Neo-Kantian (Vagnetti 2018). In Lotze's major work, Logik, Lotze has a central focus on validity, in its most general form as he used it, that investigates various related topics, i.e., concepts, language, etc. (Vagnetti 2018; Lotze 1888). Furthermore, we observe that Frege's work is so similar to Lotze, that it seems questionable to call his outlook 'Platonism'. Therefore, attributing 'Platonism' to Frege may be a slight misnomer. This paper's entirety is mostly a synthesis of a variety of articles related to Frege, Lotze, and their respective outlooks and the original works of Frege and Lotze that I use to support the view that the term 'Platonism' is a slight issue when predicated to Frege. As such, I include an overview of Frege's treatment in other work that highlights the usage of the term 'Platonism' and how broad its uses tend to be utilized (Balaguer 2006; Burge 1992). In sum, it is observed that the general label 'Platonism' becomes less appropriate when we consider Lotze in the picture and contrast Lotze alongside Mr. Frege. Overall, this paper is just an explanatory one of Mr. Frege, the Platonist, and the issues of applying the term 'Platonism' onto him as his views are seemingly more of a segue from Lotze.

Keywords: Frege, Lotze, number, objectification, Platonism, validity.

Для цитирования: Sierra D. Mr. Frege, The Platonist // Логико-философские штудии. 2021. T. 19, № 2. С. 136 144. DOI: 10.52119/LPHS.2021.72.65.013.

\section{Overview}

Frege being a central figure in the history of analytic philosophy has led to various labels to be attached to him. One label commonly applied is that he is a Platonist. Even with that label, there are further distinctions under the Platonist banner that are up to interpretation or argued for when applied to Frege. Nonetheless, there seem to be better candidates of Platonism that lead to a more accurate portrayal of the Platonist that Frege is. In this case, I will utilize the two types of Platonism that Reck (2005)

\footnotetext{
${ }^{1}$ Daniel Sierra, graduate student, Department of Philosophy, California State University, Long Beach. daniel.sierra01@student.csulb.edu
} 
offers. The article itself is excellent in this endeavor as it provides a picture of Frege in the context of his writings. This is very important as the term 'Platonism' taken as is can lead to views that are classical as found in many of Plato's writings; in the article by Reck, he considers such views as naïve Platonism. However, what I also find significant is Frege's influences, which led him to have these views in the first place. So, I will mention Rudolf Hermann Lotze's writings that appear to contain pre-Fregean ideas that need to be taken seriously when considering Frege's Platonism. Frege's influence from Lotze is interesting because it is not as widely studied as I would have expected, given that the influence is apparent when considering how similar their writings are in the approach of certain concepts. That said, I will only consider particular examples in relation to Frege's supposed Platonism. After, I will bring in examples of what other work says about Frege and his Platonism. Lastly, I will conclude by stressing the main issues regarding the appropriate Platonism once identified. I will close this paper by just saying that I find that the term 'Platonism' itself, though useful, raises a variety of issues with respect to Frege's influences. So, the general label 'platonism' becomes less appropriate when we consider Lotze in the picture. I also won't argue for or against any particular view of Platonism as I think that is not what I intend to do, nor is it the purpose of this paper. Overall, this paper is just a short explanatory one of Mr. Frege the Platonist, and the issues of applying the term 'Platonism'.

\section{The Sort of Platonism that Frege is}

Reck (2005) offers two candidates of Platonism suitable for Frege; these are 'Platonism A' and 'Platonism B'. Platonism A has three principles (Reck, p. 7). The first principle is the view that numbers are objects in the same sense as physical objects in our physical world in that they exist, are independent, have determinate properties and the like; however, numbers are not in our physical world, are not in our mental world, but rather in a conceptual world of abstract objects (p. 5). The second principle of Platonism A is that it attempts to explain truth and objectivity as correspondence from the idea of objecthood and on the notion of reference (p. 6-7). The third principle of Platonism $\mathrm{A}$ is that it has an issue with accessibility in terms of abstract objects, regardless of whether our arithmetic is consistent and non-contradictory as a system (p. 7-8). For now, let us focus primarily on the first principle of Platonism.

On the other hand, Platonism B contrasts with Platonism A in that we do not consider the world of abstract objects and its assumption; instead, we look at the arithmetic judgements and inferences such that they are clarified in that the judgements are well-formed, in an objective manner, their truth values are fully considered, and their validity holds; so, the system is based only on logical assumptions, not with the use of any other assumptions, i.e., the empirical or abstract (Reck, p. 14-16). This is done so that expressions used to refer to numbers may be used in the linguistic role of object names. 'Objecthood', for Platonism B, of numbers means that their 
objective determinateness is based on the basic laws/axioms of logic (p. 15). What is fundamental for Platonism B is that the key idea is the objective determinateness of numbers as logical objects (p. 15).

Reck (2005) provides examples from Frege's writings regarding both Platonism A and Platonism B. For Platonism A, the examples seem rather inappropriate for Platonism A (Reck, p. 8). Frege is actually uninterested in the idea that mathematical objects that are found without the use of our senses or even our mind. In other words, the problem of access does not get raised, which is a principle for Platonism A (p. 8). For example, in the passage:

In arithmetic we are not concerned with objects which we come to know as something alien from without through the medium of the senses, but with objects given directly to our reason and, as its nearest kin, utterly transparent to it (Frege, FA $\S 105$, p. 115).

Frege seems somewhat dismissive of the accessibility of objects. Instead, it seems as if he presumes that they are there. Another example to consider gives a different picture of objectivity, especially in arithmetic or number (Reck, p. 9). As in, "What is objective ... is what is subject to laws, what can be conceived and judged, what is expressible in words" (Frege, FA $\S 26$, p. 35). So, Frege is attributing objectivity with the capability to infer or judge from what is restricted from laws. Moreover, there is no discussion of an external connection of an abstract platonic realm. Keeping in mind Platonism A, the objecthood of numbers is conceived of in a contrary manner than what is expected from Platonism. Frege conceives of numbers as object words, thought of as a name, in a linguistic manner, and not as a predicate that can be affirmed on to a thing (Reck, p. 10). Frege is instead critical of the use of numbers as predicates as it affects their meaning and that a number's self-subsistence removed from the use of a sentence/proposition is not what he means to affirm (Frege, FA $\S 60$, p. 72). Therefore, Frege finds it imperative how words or phrases referring to numbers are used within the context of the proposition in which they appear.

It follows that Frege fits better with Platonism B given how Platonism A is unsuitable, but some elucidation needs to be provided before we move forward. What needs to be elucidated is Frege's approach to numbers. He does this by informal analysis of our arithmetic judgements in terms of their inferential structure and content (Reck, p. 10). By doing so, Frege can develop a logical system by working with what was synthesized via his analysis of mathematical judgements (p. 10-11). When Frege analyzes arithmetic judgements, he finds results worth noting. One result is that if we try to understand arithmetic sentences formally, empirically, or in terms of psychology, we'll misinterpret them. Rather, Frege wants to interpret arithmetic sentences through his notion of concepts, which is central to Frege's logicism (p. 11-13). Therefore, the objectivity of these sentences is closely related to the objectivity of them and their inferences conceptually: in other words, their logicality. In sum, his overarching starting 
point is the objectivity of logical sentences and inferences; thereby, all such sentences are objective, logical reductions (p. 11-13). Another result is that arithmetic sentences do not just deal with or utilize concepts or a concept in the general sense. Instead, the bijective relation of two concepts onto each other is vital: Frege's definition of number is derived from this notion (p. 13-14). A further result regarding arithmetic sentences is that they can at all instances be analyzed such that they contain number words or numerals being used as object names. Yet, to be able to talk about numbers as objectively existing logical objects, certain criteria need to be met (p. 11-13). Namely, it needs to be made clear that every statement expressing an arithmetic sentence is objectively true or false. Truth needs to be clarified in terms of its logical bases. Frege's project Foundations of Arithmetic endeavors to do all of this and more when considering his other writings (p. 12-13).

Frege's defines number keeping in mind the connection of concepts with numerical statements, extensions of concepts, one-to-one equinumerous mappability of concepts, and numerical words/numerical expressions are to be treated as object names - akin to names for extensions of concepts (Reck, p. 12-13). As follows, "the number which belongs to the concept $\mathrm{F}$ is the extension of the concept "equal to the concept F" (Frege, FA § 68). Later in Foundations of Arithmetic, Frege has an interesting response to his own definition:

My definition lifts the matter onto a new plane; it is no longer a question of what is subjectively possible but of what is objectively definite. For in literal fact, that one proposition follows from certain others is something objective, something independent of the laws that govern the movements of our attention, and something to which it is immaterial whether we actually draw the conclusion or not (Frege, FA $\S 80)$.

Moreover, extensions are logical objects, for Frege. So, when applied to extensions of concepts, words that refer to extensions are used as object names (Reck 2005: 1516). Given that, arithmetic sentences and inferences have a foundation on logical assumptions. Now we may say that Frege's Platonism can be categorized as a kind of Platonism B: briskly as objectifying numbers as logical objects/concepts.

\section{Lotze's Influence on Mr. Frege}

Why does Frege even have such views of number? One way to answer that is to look at one of his influences, Hermann Rudolf Lotze, to provide a general overview to compare with later. Typically labeled as coming from a Neo-Kantian school, Lotze's notion of validity, concepts, numbers, and the like influenced Frege's own formulations (Vagnetti 2018: 129-130). Many examples of such may be found in Lotze's Logik. In the Logik, some of the ideas Lotze argues for are against the reduction of thought to representative properties, i.e., psychologism, and puts forth his own conception of validity (Vagnetti, 
p. 130). Validity for Lotze is "the reality itself of our thought's contents, the famous 'third realm', a third path that positions itself between transcendent reality and the subjectivism of the psychological process which creates representations" (p. 130). Here, Lotze is reworking Plato's idea of the forms and attempting to assimilate it to Kantian philosophy that he was interested in. Lotze views Plato's world of forms like that of a world of pure validity to show that ideas or concepts are not in the real world (p. 130). This allows Lotze to argue that the logical content of thought is autonomous and objective, without the need of an individual subjectively, and simultaneously reconsider Kant's view of the transcendental since logical objectivity is not concerned with ontology but with the logical in itself. Moreover, for Lotze, validity does not entail existence (p. 130). I should also mention that Lotze uses the term 'logic' flexibly as he uses it to refer to epistemology (p. 130).

Examples of Frege's influence derived from Lotze may be found directly in several of Frege's writings. For example, a clear discussion of another realm is discussed without referencing any sort of ontology is in his Thought:

A third realm must be recognized. Anything belonging to this realm has it in common with ideas that it cannot be perceived by the senses, but has it in common with things that it does not need an owner so as to belong to the contents of his consciousness (Frege 2001: 25).

Frege immediately after describes thoughts belonging in this realm as needing no owner: 'thoughts' for Frege are something that can be ascribed a truth-value and is a sense of a sentence. Moreover, thoughts are imperceptible that are neither in the actual world nor what we typically call ideas, as in the subjective case of experience. Keeping in mind Lotze, the discussion of the other realm is eerily similar to Lotze's discussion of universal validity:

Universal validity and truth are two prerogatives which even ordinary language ascribes and confines to those connexions of ideas which thought alone is supposed to establish. Truth is familiarly defined as the agreement of ideas and their cominations with their object and its relations (Lotze 1888, Book I: Introduction, III).

In this short section in Lotze's Logik, it is apparent that Lotze is concerned with different matters as opposed to Frege, but the spirit is the same in the sense that thoughts or concepts affirm a truth-value. Nevertheless, Frege is also not wholly concerned with thoughts, but with mathematics and logic. Similarly, Lotze is as well, which he mentions throughout his Logik. Surprise!

As discussed in the previous section regarding Platonism B, Frege is interested in objectifying mathematics as logical objects/concepts. However, Frege's interests are not just confined to mathematics, but also in a theory of meaning, Sense \& Reference. In Frege's On Sense $\&$ Reference, he argues that identity statements of the form ' $a=b$ ' 
cannot always be known or understood a priori; so, ' $a$ ' and ' $b$ ' have the same reference, but they contain in themselves a different sense. The overlap between Frege's two interests is evident when we have an example at hand:

The reference and sense of a sign are to be distinguished from the associated idea. If the reference of a sign is an object perceivable by the senses, my idea of it is an internal image, arising from memories of sense impressions which I have had and acts, both internal and external, which I have performed. Such an idea is often saturated with feeling; the clarity of its separate parts varies and oscillates. The same sense is not always connected, even in the same man, with the same idea. The idea is subjective: one man's idea is not that of another. There result, as a matter of course, a variety of differences in the ideas associated with the same sense. A painter, a horseman, and a zoologist will .probably connect different ideas with the name 'Bucephalus'. This constitutes an essential distinction between the idea and the sign's sense, which may be the common property of many and therefore is not a part of a mode of the individual mind. For one can hardly deny that mankind has a common store of thoughts which is transmitted from one generation to another (Frege 1990).

This eclectic application of logic and mathematics is characteristic in Frege's writings; however, Lotze is also eclectic in his approach to language, logic, and mathematics. It is conceivable that Frege drew influence in Lotze's work. In his Logik, reference to syllogism by substitution is mentioned when discussing certain argument forms that require us to know the parts of a conclusion mean. Lotze continues, "This, however, if it is not to be learnt simply by experience, can only be arrived at by thought if all these mutually related parts are pure quantities, and the relations between them those of mathematical combination and separation" (Lotze, Logik 111). How Lotze symbolizes such arguments is not all too important for my purposes, they are rather awkward, but he attempts to show a qualitative relationship via the use of calculation. Or in Lotze's words that we can picture Frege studying:

The fact that the use of the syllogism by substitution is confined to mathematics, cannot hinder us from giving it a place in the systematic series of forms of thought. For in the first place we must not forget that calculation in any case belongs to the logical activities, and that it is only their practical separation in education which has concealed the full claim of mathematics to a home in the universal realm of logic (Lotze 1888: 112).

The semblance in Frege's theory of reference based on his notion of sense between Lotze's discussion of syllogism by substitution is evident when you attempt to recognize that Frege is focusing more on sense while Lotze is recommending the use of calculation onto language and arguments. 
I want to conclude this section by saying that Lotze's Logik is fruitful in identifying Frege's overall influence, so one may certainly write an entire book on this topic, which is not what I am attempting to do. Even so, I want to point out one last excerpt from the introduction of the Logik to highlight Frege's Platonism:

We may describe this first operation of thought as the beginning of an objectification of the subjective; and I take advantage of this expression to guard against a misunderstanding and so illustrate the simple meaning of what I have said above. It is not objectivity in the sense of some sort of real existence which would subsist though nobody had the thought of it, that, by the logical act of creating a name, is accorded to the subject-matter to which that act gives rise. The true meaning of the first act of thought is best exemplified by those languages which have maintained the use of the article... ...The logical objectification, then, which the creation of a name implies, does not give an external reality to the matter named (Lotze 1888: 3).

Similar to Frege's objectification of mathematics, Lotze approaches 'objectification' in a linguistic fashion by analyzing parts of language without a direct claim of existence.

\section{Balaguer and Burge on Frege}

Work on Frege portrays him typically as a type of Platonist B with slight differences. Examples of such portrayals may be found by Tyler Burge and Mark Balaguer. However, they do tend to directly posit existence claims of mathematical objects within their descriptions of Frege. Understandably, this is what Frege's view seemingly leads to, but jumping head on to existence as is, is different from logical existence. Caution is thereby necessary when discussing Frege, as Reck recommends. In comparison, Balaguer describes Frege more as a placeholder for his description of mathematical Platonism. He is not all too concerned whether or not Frege is a Platonist, but rather the notion of mathematical Platonism. This section only exemplifies the treatment of the label 'platonism' when applied to Frege and how varied it can be. Though the label has commonalities in view of the authors, how they picture Frege differs slightly.

Burge in his article Frege on Knowing the Third Realm, describes Frege firstly as "a Platonist about logical objects, functions, and thought contents" (Burge 1992: 634). Burge further adds that Frege is mostly a relaxed Platonist in terms of mathematics who stipulates that there are objects such as numbers, functions, and etc., that are to be regarded as abstract. Burge recognizes the importance of mathematics in Frege's work (Burge, p. 636). More importantly, Burge notes that Frege uses platonic language metaphorically when depicting knowledge and that Frege does not develop this any further (p. 636-637). What Burge also identifies is that Frege refers to numbers, concepts, and thoughts as objective; however, Burge clarifies what Frege means behind 
'objective' in that they are not created by the mind, such that objective objects are subject to laws and accessible to any rational agent (p. 637).

Balaguer has different intentions when depicting Frege as he wants to highlight and survey the differences between mathematical realism and anti-realism (Balaguer 2006: 35-36). The paper itself is on the metaphysics of mathematics, but he begins with Frege's standard view that later leads to metaphysical views. As in, object-platonism, which Balaguer defines as "the view that the mathematical realm is a system of abstract mathematical objects, such as numbers and sets, and that our mathematical theories, e.g., number theory and set theory, describe these objects" (Balaguer, p. 41-42). Object-platonism, for Balaguer, falls under mathematical realism, which is popularly attributed to Frege. Balaguer describes mathematical realism as the view "that there exist abstract mathematical objects, and that our mathematical theories or axioms provide true descriptions of such objects" (Balaguer, p. 36 \& 41-42). Balaguer's survey indicates that philosophers of mathematics use 'platonism' and 'realism' interchangeably as they assume that Platonism is the only defensible version of realism.

\section{Concluding Thoughts}

I have highlighted several aspects of what may be said about Frege. Considering that several of his ideas are influenced by Lotze and what other work says about Frege, there may be several disputes regarding Frege being depicted as falling under Platonism B. Unsurprisingly, Reck admits this by giving us three main problems regarding Platonism B: (1) how are we to grasp the objectivity of the logical laws that everything depends on for Frege, (2) why is it that Frege considers his reduction of numbers to the correct one, and (3) can one develop arguments that support Frege's platonic theses but is not susceptible to Russel's Paradox. For this paper, (1) and (2) are the most important. For (1), if interpreted to apply to logic, Frege gives a strange answer to this in his Thought: "To the Grasping of thoughts there must then correspond a special mental capacity, the power of thinking" (Frege 2001). On (2), I think if you consider his influence from Lotze and his claims about logic, an answer may be found, whether one considers this to be acceptable or not. Frege considers logic to be effective due to their timelessness, such that they are authoritative over thoughts and their attainment of truth (Burge 1992).

I want to close by mentioning that the word 'platonism' is an issue at times when predicated on Mr. Frege. Why is it that we cannot just refer to this system that Frege proposes, that is more akin to Lotze than to Plato, 'Fregeanism' in general or 'mathematical objectification', especially since it is more fitting and it has less baggage surrounding it. Pedagogically, I understand the value in using 'platonism' to give a 
Daniel Sierra. Mr. Frege, The Platonist

background to his ideas, which led me to write this paper. Still, Frege is working beyond the standard naïve-platonistic picture and even Platonism A. I think there is a degree of courtesy behind this as it saves a lot of misinterpretations and enables a reader to be more cautious or clear-headed when reading Frege's work. I believe that this is a minor claim and can be readily accepted once we saw which of the two types of Platonism fits Frege the best and when we see how Lotze influenced Frege. In short, 'platonism' is a slight misnomer that we should do away with and consider referring to his work as something more appropriate or fitting when we look at his main focus: numbers!

\section{References}

Balaguer 2006 - Balaguer M. Realism and Anti-Realism in Mathematics // Philosophy of mathematics / ed. by A. D. Irwine. North Holland, 2006. P. 35-101.

Burge 1992 - Burge T. Frege on Knowing the Third Realm // Mind. 1992. Vol. 111, no. 404. P. 633-650.

Frege 1990 - Frege G. On Sense And Reference // Meaning and Reference / ed. by A. W. Moore. OUP, 1990.

Frege 2001 - Frege G. Thought // Analytic Philosophy: An Anthology / ed. by A. P. Martinich and E. D. Sosa. Blackwell, 2001. P. 19-31.

Frege 1960 - Frege $G$. The Foundations of Arithmetic: A Logico-Mathematical Enquiry. Into the Concept of Number. New York: Harper \& Row, 1960.

Lotze 1884 - Lotze H. Logic, in Three Books, of Thought, of Investigation, and of Knowledge. Clarendon Press, 1884.

Vagnetti 2018 - Vagnetti M. The Logik by Rudolf Hermann Lotze: The Concept of Geltung // Philosophical Readings. 2018. Vol. 10, no. 2.

Reck 2005 - Reck E. H. Frege on Numbers: Beyond the Platonist Picture // Harvard Review of Philosophy. 2005. Vol. 13, no. 2. P. 25-40. 